\title{
Development of controlled release dexketoprofen tablets and prediction of drug release using Artificial Neural Network (ANN) modelling
}

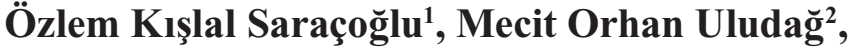 \\ Elif Derya Özdemir ${ }^{2}$, İsmail Tuncer Değim ${ }^{\circledR 3}$
}

\begin{abstract}
${ }^{1}$ Department of Pharmaceutical Technology, Faculty of Pharmacy, Gazi University, Ankara, Turkey, ${ }^{2}$ Department of Pharmacology, Faculty of Pharmacy, Gazi University, Ankara, Turkey, ${ }^{3}$ Department of Pharmaceutical Technology, Faculty of Pharmacy, Biruni University, Topkapı, İstanbul, Turkey
\end{abstract}

\begin{abstract}
Dexketoprofen trometamol (DT) is an active $S(+)$ enantiomer of ketoprofen, and a non-steroidal antiinflammatory agent. DT has a short biological half-life and the dosing interval is quite short when there is a need to maintain the desirable effect for longer time periods. Consequently, a controlled release DT tablet was designed for oral administration aiming to minimize the number of doses and the possible side effects. Calculations of the parameters for controlled release DT tablets were shown clearly. Controlled release matrix-type tablet formulations were prepared using hydroxypropyl methylcellulose (HPMC) (low and high viscosity), Eudragit RS and Carbopol, and the effects of different polymers on DT release from the tablet formulations were investigated. The dissolution rate profiles were compared and analyzed kinetically. An Artificial Neural Network (ANN) model was developed to predict drug release and a successful model was obtained. Subsequently, an optimum formulation was selected and evaluated in terms of its analgesic and anti-inflammatory activity. Although the developed controlled release tablets did not have an initial dose, they were found to be as effective as commercially available tablets on the market. Dissolution and in vivo studies have shown that the prepared tablets were able to release DT for longer time periods, making the tablets more effective, convenient and more tolerable.
\end{abstract}

Keywords: Dexketoprofen. Controlled release. Oral tablet. HPMC. Eudragit. Carbopol.

\section{INTRODUCTION}

Controlled release systems are intended to release the active substance at the desired rate for longer time periods at the site of action. Controlled release dosage forms offer certain advantages over conventional dosage forms, providing the appropriate effects with lower doses and able to maintain constant plasma levels. Controlled release dosage forms lower the likelihood of side effects, which is important for patient compliance.

*Correspondence: . T. De im, Department of Pharmaceutical Technology, Faculty of Pharmacy, Biruni University, Topkap1 34010, stanbul, Turkey. Tel: +90 21240912 12/1340; Fax: +90 21241646 46. E-mail: tdegim@ biruni.edu.tr
Dexketoprofen trometamol (DT) is an $\mathrm{S}(+)$ enantiomer of ketoprofen and acts as an analgesic, nonsteroidal anti-inflammatory drug. The more lipophilic form of ketoprofen is also known as DT.

The chemical name of dexketoprofen is $S$-(3benzoylphenyl) propionic acid, with the formula C16H14O3. The molecular weight of DT is $254,284 \mathrm{~g} / \mathrm{mol}$. Free acid dexketoprofen is almost insoluble in water, but soluble in chloroform, ether and ethanol. Dexekoprofen trometamol is $S$-(3-benzoylphenyl) propionic acid tromethamine salt. The trometamol salt of dexketoprofen readily dissolves in water (Chandrasekharan, 2007). The maximum plasma concentration (tmax) of DT is between 0.25 to 0.75 hours and its biological half-life is around 0.5 hours (Barbonaj, Antonijoan, Gich, 2001). DT is a good 
candidate for controlled release, in that its short half-life requires it to be taken more frequently. DT has a rapid onset of action, given its potency, and is less of an irritant than ketoprofen to the stomach and intestinal cells. These can be underlined as the main advantages of DT over ketoprofen (Iohom et al., 2004). DT is reported to be very efficient in osteoarthritis, dysmenorrhea and in dental or orthopedic surgery (Beltran et al., 1998). For many years, the studies focusing on the development of therapeutic drugs for the treatment of various diseases have sought to develop new molecules or better formulations, although the reduction of dosing intervals by way of a controlled release drug delivery system may also be helpful in increasing patient compliance and minimizing the possible side effects of known drugs. Controlled release systems can provide enough drug molecules to the targeted regions or tissues, making and it possible to overcome all of the mentioned undesired effects.

The application of artificial neural networks (ANNs) for pharmaceutical development and the optimizing of dosage forms has gaining importance, becoming a hot topic in the pharmaceutical field (Takayama, Takayama, Nagai, 1997; Takayama, Fujikawa, Nagai, 1999; Kesavan, Peck, 1996; Wu et al., 2000; Chen et al., 1999). Generally, classical statistical optimization techniques identify nonlinearities between data sets and responses, and these complex relationships create some problems in interpretations and result in low prediction abilities. ANN show superiority as a modeling technique for data sets demonstrating nonlinear relationships, and also for both data fitting and successful predictions (Bourquin et al., 1997; Bourquin et al., 1998a; Bourquin et al., 1998b). ANN is a learning system based on a computational technique that can simulate the neurological processing approach of the human brain and can be applied to quantify the nonlinear relationship between causal factors and pharmaceutical responses by means of iterative training of dissolution experiments (Achanta, Kowalski, Rhodes, 1995). This has been successfully applied to many dosage systems, including matrix systems or controlled release systems, for development and scaling up (Takka, Rajbhandari, Sakr, 2001; Rekhi et al., 1999). The influence of various formulation variables or parameters on the release of drugs from matrices has been investigated in literature for aspirin and Eudragits (Jovanovic et al., 1997a; Jovanovic et al., 1997b). Investigations into the effects of the ratio of polymer, as well as compression pressure and tablet porosity, were investigated, identifying ANNs as a useful tool for identifying the most important factors affecting drug release (Jovanovic et al. 1997a; Jovanovic et al. 1997b). The objectives of the present study are to develop a controlled release DT tablet for oral use and to optimize the formulation through ANN. A series of controlled release DT tablet formulations have been developed, and drug release at a controlled rate has been achieved. Dosing intervals and some possible side effects were also aimed to be minimized through the use of a developed controlled release formulation. In general, controlled release dosage forms contain much higher doses than conventional tablets, although in the present study, the amount of DT was kept constant (75 $\mathrm{mg}$ ) in all formulations so as not to increase the risk of side effects and intolerance. Parameter calculations are shown clearly and the desired drug release rate and release period were determined, from which the target DT release profile was calculated. Hydroxypropyl methylcellulose (HPMC) (low and high viscosity), Eudragit RS and Carbopol were used as polymers, and the tablets were formed through direct compression or after wet granulation. The same pressure and preparation parameters were used for all formulations. Finally, controlled release matrix-type tablet formulations were developed, and their dissolution rates and profiles were obtained and compared with commercially available immediate release tablets. The effects of using different polymers in the formulation on drug release were examined using ANN. The selected formulation was subjected to in vivo experiments, and its analgesic and anti-inflammatory properties were investigated using male Wistar albino rats. The developed tablets were found to be as effective as commercial tablets.

\section{MATERIAL AND METHODS}

\section{Designing controlled release DT tablets}

The pharmacokinetic parameters of DT were obtained from literature (Barbonaj, Antonijoan and Gich, 2001) as follows:

Dose $=25 \mathrm{mg}$

$\mathrm{V}_{\mathrm{d}}=17.220 \mathrm{~L}$

$\mathrm{k}_{\mathrm{el}}=0.271$ hour $^{-1}$

$\mathrm{k}_{\mathrm{a}}=1.653$ hour $^{-1}$ (Absorption rate constant was calculated from data available in literature) 
Other parameters were selected for further calculations as follows:

$\mathrm{C}_{\text {opt }}=0.850 \mathrm{mg} / \mathrm{L}$

$\mathrm{N}=0.250$

Calculating the theoretical release rate and dose for DT (Bourne, 2002):

1 - $B=0.850 \times 17.220=14.637 \mathrm{mg}$ (amount of drug in the body)

2- $\mathrm{k}_{\mathrm{r} 0}=14.637 \times 0.271=3.967 \mathrm{mg} /$ hours (desired release rate)

3- $\Delta \mathrm{t}=\left(1 / \mathrm{k}_{\mathrm{el}}\right) \times\left(\ln \left(\mathrm{k}_{\mathrm{a}} /\left(_{\mathrm{ka}}-\mathrm{k}_{\mathrm{el}}\right)\right)\right)=0.661$ hours (time taken to decrease blood drug concentration after all drug molecules released)

4- $\mathrm{t}_{\mathrm{d}}=\left(1 / \mathrm{k}_{\mathrm{el}}\right) \times(\ln (1 /(\mathrm{N}))=5.115$ hours (time to decrease blood drug concentration to allowed level)

5- $\mathrm{h}=24($ dose interval $)-\left(\Delta \mathrm{t}+\mathrm{t}_{\mathrm{d}}\right)=18.224$ hours (desired period for drug release)

Total dose $=18.224 \times 3.967=72.295 \mathrm{mg} \rightarrow 75 \mathrm{mg}$ DT was decided to be used for all tablets.

\section{Tablet preparation}

The DT content of all tablets was $75 \mathrm{mg}$. Low and high viscosity HPMC (HPMC-D-Y HPMC), Carbopol 934P NF and Eudragit RS were used as polymers. Lactose was used as a filler. Aerosil 380 was used as a lubricant to improve the flow properties of formulations.

The effects of content on flowability and compressibility were examined. Wet granulation or direct compression were used for tableting. The wet granulation method was used for the formulations containing Eudragit RS. Eudragit RS was used as a binder, and 10, 15 and $20 \%$ of Eudragit RS in ethanol was used for granulation for formulations F7, F8 and F9, respectively. Other substances were added and mixed, and then granules were formed using a stainless steel mixer and granulator (Erweka GmbH, Germany) and a sieve (1250 mesh). Aerosil was added after drying as a glidant and mixed; finally, the tablets were pressed using a single punch tablet press (Korsh, Erweka GmbH, Germany). Differential Scanning Calorimetry (DSC 60 Shimadzu, Japan) scans of the individual materials or mixtures for each formulation were obtained, and no significant interactions were recorded. The contents of the tablets are presented in Table I.

Table I: Tablet formulations and contents (mg)

\begin{tabular}{|c|c|c|c|c|c|c|c|}
\hline Formulation & DT & $\begin{array}{c}\text { HPMC } \\
\text { (Low viscosity) }\end{array}$ & $\begin{array}{c}\text { HPMC } \\
\text { (High viscosity) }\end{array}$ & $\begin{array}{c}\text { Eudragit } \\
\text { RS } \\
\text { (Wet granulation) }\end{array}$ & $\begin{array}{l}\text { Carbopol } \\
\text { 934P NF }\end{array}$ & Lactose & $\begin{array}{c}\text { Aerosil } \\
\%\end{array}$ \\
\hline $\mathrm{F} 1$ & 75 & 25 & 0 & 0 & 0 & 75 & 1 \\
\hline $\mathrm{F} 2$ & 75 & 50 & 0 & 0 & 0 & 50 & 1 \\
\hline F3 & 75 & 75 & 0 & 0 & 0 & 25 & 1 \\
\hline F4 & 75 & 0 & 25 & 0 & 0 & 75 & 1 \\
\hline F5 & 75 & 0 & 50 & 0 & 0 & 50 & 1 \\
\hline F6 & 75 & 0 & 75 & 0 & 0 & 25 & 1 \\
\hline F7 & 75 & 0 & 0 & $\begin{array}{c}3.1 \pm 0.05 \\
(\% 10 \text { solution was used })\end{array}$ & 0 & 75 & 1 \\
\hline
\end{tabular}


Table I: Tablet formulations and contents (mg)

\begin{tabular}{|c|c|c|c|c|c|c|c|}
\hline Formulation & DT & $\begin{array}{c}\text { HPMC } \\
\text { (Low viscosity) }\end{array}$ & $\begin{array}{c}\text { HPMC } \\
\text { (High viscosity) }\end{array}$ & $\begin{array}{c}\text { Eudragit } \\
\text { RS } \\
\text { (Wet granulation) }\end{array}$ & $\begin{array}{l}\text { Carbopol } \\
\text { 934P NF }\end{array}$ & Lactose & $\begin{array}{c}\text { Aerosil } \\
\quad \%\end{array}$ \\
\hline F8 & 75 & 0 & 0 & $\begin{array}{c}4.3 \pm 0.05 \\
\text { (\%15 solution was used) }\end{array}$ & 0 & 75 & 1 \\
\hline F9 & 75 & 0 & 0 & $\begin{array}{c}5.1 \pm 0.05 \\
(\% 20 \text { solution was used })\end{array}$ & 0 & 75 & 1 \\
\hline F10 & 75 & 0 & 0 & - & 25 & 75 & 1 \\
\hline F11 & 75 & 0 & 0 & - & 50 & 50 & 1 \\
\hline F12 & 75 & 0 & 0 & - & 75 & 25 & 1 \\
\hline F13 & 75 & 25 & - & - & 25 & 50 & 1 \\
\hline F14 & 75 & 25 & - & - & 50 & 25 & 1 \\
\hline F15 & 75 & 25 & - & - & 75 & - & 1 \\
\hline F16 & 75 & 50 & - & - & 25 & 25 & 1 \\
\hline F17 & 75 & 50 & - & - & 50 & - & 1 \\
\hline F18 & 75 & 75 & - & - & 25 & - & 1 \\
\hline F19 & 75 & 37.5 & - & - & 37.5 & 25 & 1 \\
\hline
\end{tabular}

\section{Assay}

A calibration curve was obtained using DT concentrations of 50 to $0.39 \mathrm{mg} / \mathrm{ml}$ in a $0.1 \mathrm{~N} \mathrm{HCI}$ or $\mathrm{pH}$ 6.8 phosphate buffer. The analysis was performed using a spectrophotometer at $258 \mathrm{~nm}$ and $261 \mathrm{~nm}$, respectively, for the $0.1 \mathrm{~N}$ HCI and $\mathrm{pH} 6.8$ phosphate buffers. The method was adopted fully validated from literature (Mabrouk et al., 2014), and was found to be linear, reproducible and accurate.

\section{Tablet controls}

Standard tests for tablets, such as thickness and weight variations, hardness tests and friability were performed. Dissolution tests of the prepared tablets (in vitro release) were performed using the USP paddle method (USP 31), as mentioned in the delayed-release method monograph. A concentration of $750 \mathrm{ml} 0.1$ $\mathrm{N} \mathrm{HCl}$ was used for first 2 hours and $250 \mathrm{ml} 0.2 \mathrm{M}$ $\mathrm{Na} \mathrm{PO} .12 \mathrm{H} \mathrm{O}$ (tri sodium phosphate) was added. $\mathrm{pH}$ reached 6.8. If the $\mathrm{pH}$ was observed to be different, $2 \mathrm{~N}$ $\mathrm{HCl}$ or $2 \mathrm{~N} \mathrm{NaOH}$ was used to adjust the $\mathrm{pH}$. Dissolution tests were carried out for 24 hours with the paddle speed set to $50 \mathrm{rpm}$. The test was performed at $37 \pm 0.2{ }^{\circ} \mathrm{C}$, for which $5 \mathrm{ml}$ samples were taken at $0.25,0.50,1$, $1.5,2,3,4,6,8,12$ and 24 hours and replenished with fresh solutions. The samples were filtered through 0.1 $\mu \mathrm{m}$ Sartorius PTFE (Teflon) filter and analyzed using a UV spectrophotometer. Dissolution rates and data were evaluated in terms of release kinetics and release profiles using a computer program ("A Program for In vitro Dissolution Kinetics, In vitro in vivo Kinetic Correlation and Routine" (Ege University, Faculty of 
Pharmacy Department of Pharmaceutical Technology, Ver.1.0.40)).

\section{Artificial Neural Network model}

An Artificial Neural Network (ANN) program (Pythia Neural Network Designer version 1.0, Runtime Software LLC, Carson City, NV, USA) was used to determine the factors effective in drug release. The substances and their amounts in the tablet formulations (HPMC-D, HPMC-Y, Eudragait-RS, Carbopol and lactose) were used as inputs and \% releases were used as outputs.

The program calculates the transfer function and the system identifies the transfer function and relationship of mathematics to produce the available data for each neuron. Once the system learns, it is ready to make precise guesses without further experimental data (Dias, Antunes, Mota, 2004; Petrovic et al., 2012). The computer program of ANN, initially calculated a model with the best fit, and this option is used for the optimization and program gave a best fit with following number of neurons at levels from 1 to 5 were: $6,5,4,3,1$. Square deviations were obtained in this model with the lowest sums.

\section{Animal studies}

After obtaining local research ethics committee approval, the selected optimal formulation was tested on 250-300 g Wistar albino rats to assess analgesic and anti-inflammatory activity. The experiments were performed in the Gazi University Experimental Laboratory Animals Breeding and Research Center (GÜDAM, Ankara/Turkey).

The rats were kept at constant room temperature $\left(22 \pm 1^{\circ} \mathrm{C}\right)$ and humidity $(50-60 \%)$ and in a $12: 12 \mathrm{~h}$ lightdark light cycle with free access to standard rat chow and tap water. During the test, standard food in the form of pellets (Korkuteli Feed Industry T.A.S., Ankara) was provided. The Wistar albino rats were housed in accordance with international ethical rules, and guidelines for the reporting of experimental protocols were applied.

The rats were randomly assigned and divided into four groups. Prior to the experiments, the rats were given the test tablets orally. All tablets were roughly crushed and dissolved in water and administered by gavage to the rats. Each rat received the same amount of active substance (the amount active substance in the formulation was calculated and the same dose was given to the animals). The groups were assigned as follows:

Group 1: The control group (drinking water)

Group 2: F6 tablets

Group 3: Commercial tablets (Arveles ${ }^{\circledR}$ )

Group 4: Dexketoprofen group (DT)

After one hour following the oral administration, 0.1 $\mathrm{ml}$ of carrageenan $(1 \% \mathrm{w} / \mathrm{v})$ was injected intraplantarly into the right hind paw, and the same volume of saline was given to the left hind paw. After the carrageenan injection, paw volume and tail flick latencies were measured at $0,1,2,3,4,5,6,9,12$ and 24 hours. The volumes of both hind paws were measured using a plethysmometer (Ugo Basile 7140, USA) and the tail flick latencies of rats were evaluated with a tail-flick apparatus (Ugo Basile 7360, Italy). A cut-off latency of $10 \mathrm{~s}$ was used to avoid tissue damage to the tail.

The volume difference between the right and left paws was measured and regarded as paw oedema volume. The anti-inflammatory effect was calculated from the increase in paw volume using the following equation:

Increase $\%=($ right paw volume - left paw volume $) /$ left paw volume

Analgesic activity was determined using the D'Amour and Smith method (tail-flick test) (D'Amour and Simit, 1941). Nociception was assessed as the duration between the onset of thermal stimulus to the skin of the tail and the tail-flick response. The results were given as mean \pm standard error of the mean. The data was analyzed with a two-way analysis of variance followed by a Bonferroni test.

\section{RESULTS}

The thicknesses of the tablets varied from $0.241 \pm 0.003$ to $0.247 \pm 0.003 \mathrm{~cm}$. The contents of tablets were slightly different, although their weight variations were less than $2 \%$; hardness values were from $35.52 \pm 4.97$ $\mathrm{N}$ (F9) to $160.69 \pm 8.07 \mathrm{~N}$ (F4) [hardness value of F6 tablets were $112.60 \pm 8.98]$ and friability values were less than $0.98 \%$ for all formulations.

The results of the dissolution tests are presented in Figure 1 and DT observed to be released from the formulations by the time in controlled manner. 

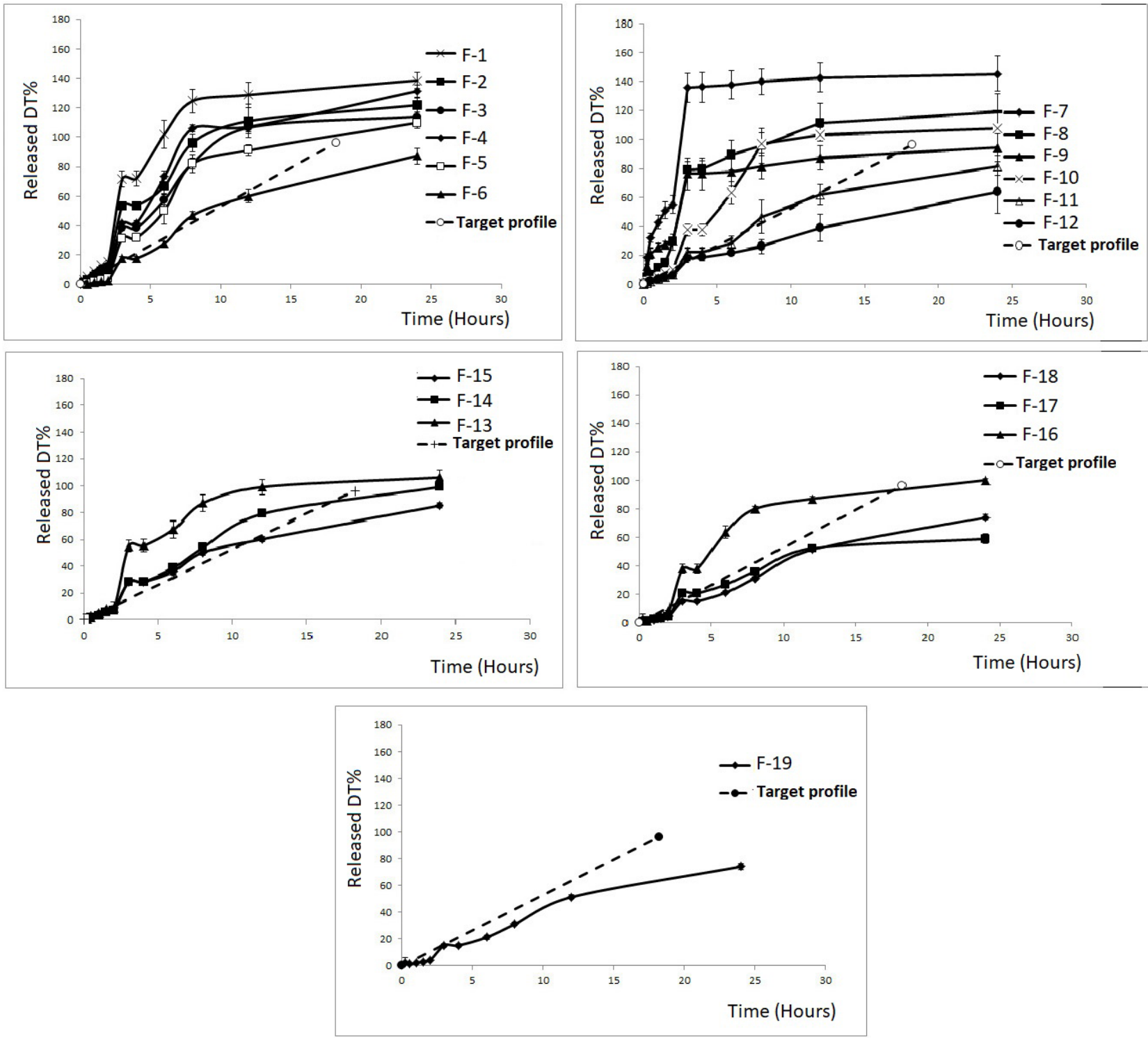

FIGURE 1 - DT release profiles of the tablet formulations, black dotted lines represent theoretical targeted drug release.

Kinetic analyses were made after the dissolution experiments. It was observed that the F6 formulation gave the closest dissolution to the target release profile, and the release profile of F6 also fitted formulation to the zero order release kinetic $(\mathrm{r} 2=0.938)$. When the best fit considering the determination constants was determined, the following results were obtained: (best to worst order)

Zero order: F10

First order: F1, F2, F3, F8, F9, F11, F12, F15, F16, F19

Hixon Crowell: F4-F5, F13, F14

Higuchi: F7, F17, F18.
The dissolution rates and profiles of commercially available tablets (Arveles ${ }^{\circledR}$, Deksofen ${ }^{\circledR}$, Elektra ${ }^{\circledR}$ and Rastel $\left.{ }^{\circledR}\right)$ were also tested, and all released more than $80 \%$ DT within 15 minutes (Data not shown). This indicated that all commercial tablets were immediate release tablets and that they can be used also for the leveling up of blood DT levels as an initial dose in controlled release formulations.

Today, there are many computer programs available that can quickly and easily perform many repetitive processes to give the desired results to difficult problems. There are many different applications of ANN in the 
pharmaceutical field (Benardos and Vosniakos, 2007). It has to date been used to develop a model for the estimation of unknown parameters without the need for extra experiments. Using the best ANN model, DT release was intended to be able to estimate like it has been done in the literature (Chansanroj et al., 2011).

The result of experimental data and the estimated data using the trained artificial neural network model are presented in Figure 2.

The effect of the formulation ingredients on release rate was investigated and the results are presented in Figure 3.

In vivo studies were performed using Wistar rats. An anti-inflammatory activity assay was performed via a carrageenan-induced paw edema model based on rat paw volumes, measured using a plethysmometer (Figure 4).

The selected formulation (F6), commercial formulation and DT powder were also evaluated for in vivo systemic anti-inflammatory activity using a carrageenan-induced paw oedema involving rats. Peak anti-inflammatory activity was shown at $270 \mathrm{~min}$, at which point inhibitory activity for oedema formation started to diminish (Figure 5).

Figure 6 shows the analgesic activities of F6, the commercial tablet and DT powder. Tail flick latencies were measured and used as a function of analgesic activity.

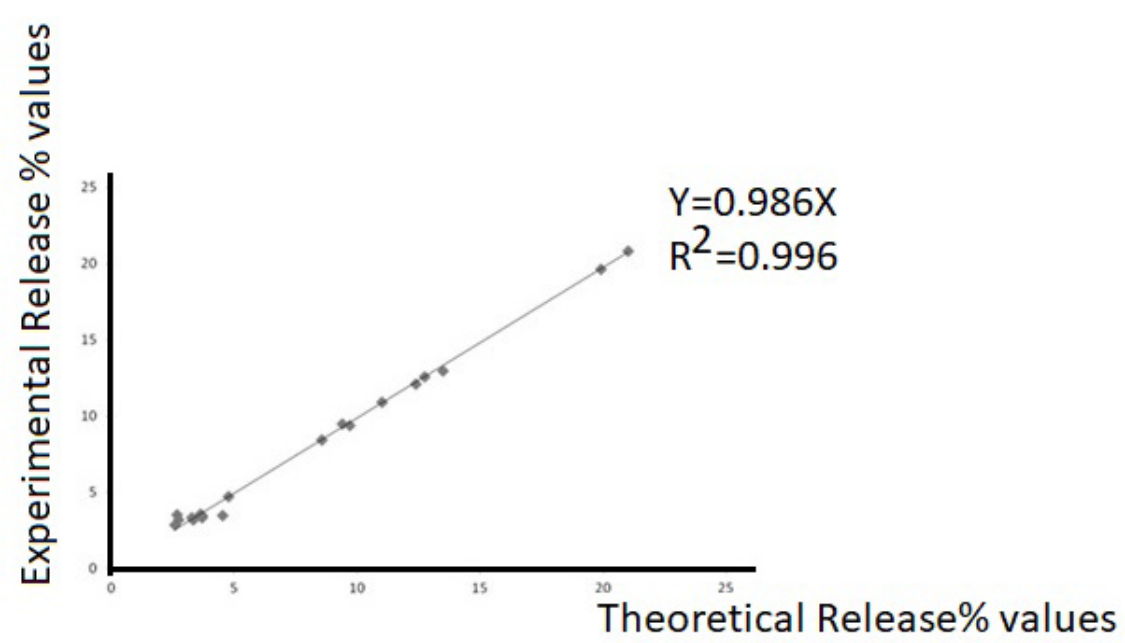

FIGURE 2 - The experimental results and theoretically obtained values produced by neural network model. 

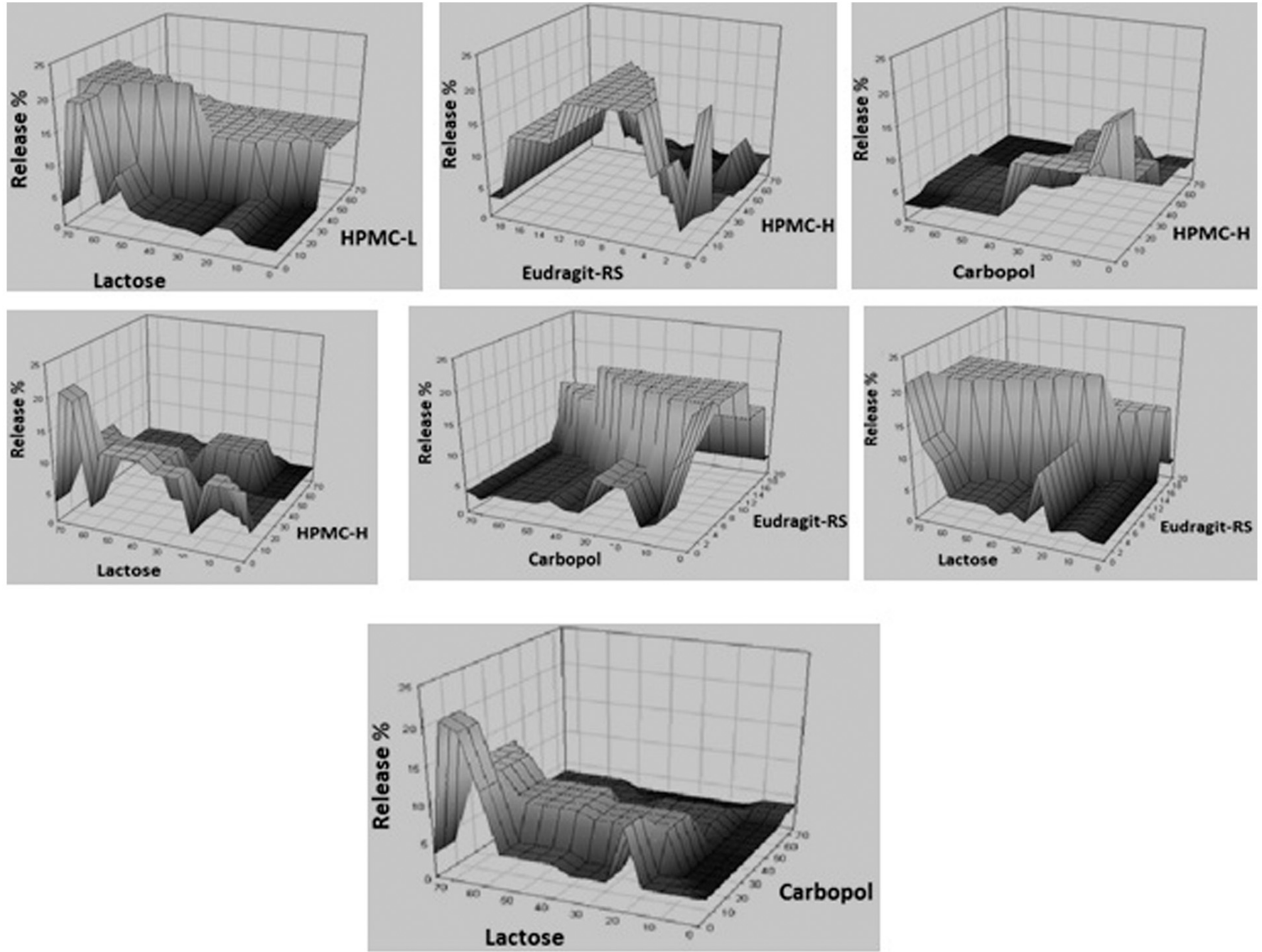

FIGURE 3 - The effects of formulation ingredients on DT releases.

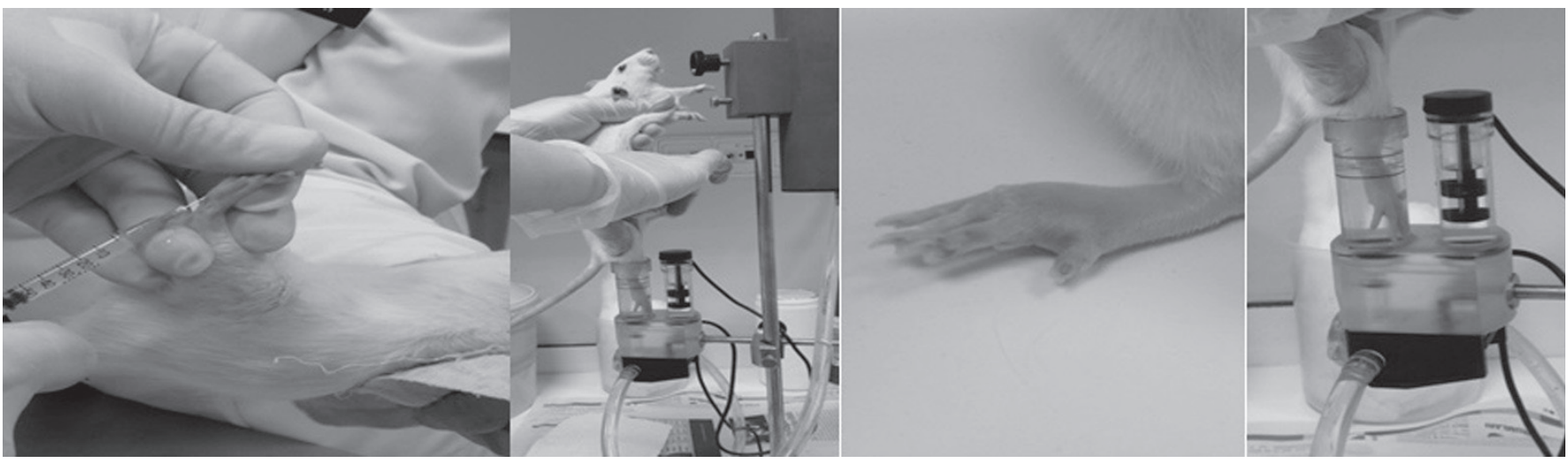

FIGURE 4 - The used inflammation model in rats. Picture shows construction of the intraplantar injection in the rat paw and the measurement. 


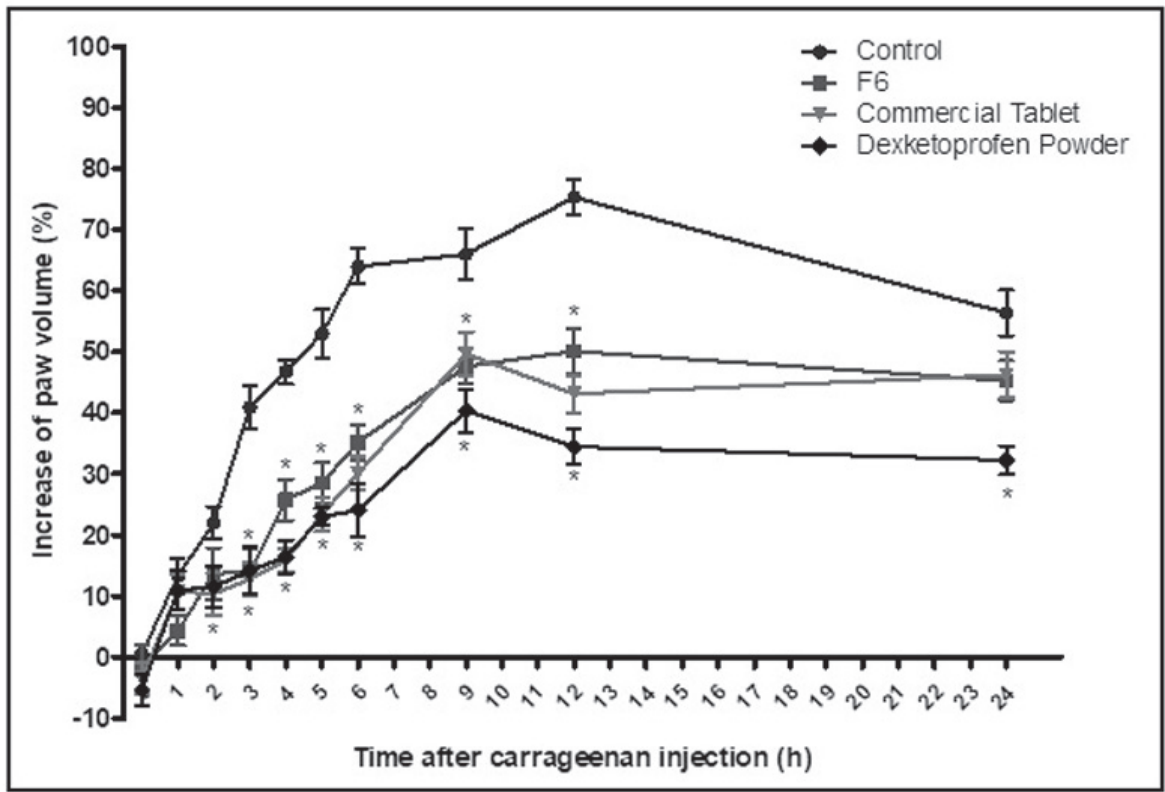

FIGURE 5 - Changes of paw volume with respect to time in different groups, the percent increase in the rat carrageenan-induced paw edema. The percentage data as an increase of paw edema volume was given as mean \pm SEM, $n=6$. Two-way ANOVA, post-hoc Bonferroni test; *different from control (F6, Arveles and Dexketoprofen (DT), *p $<0.01$.

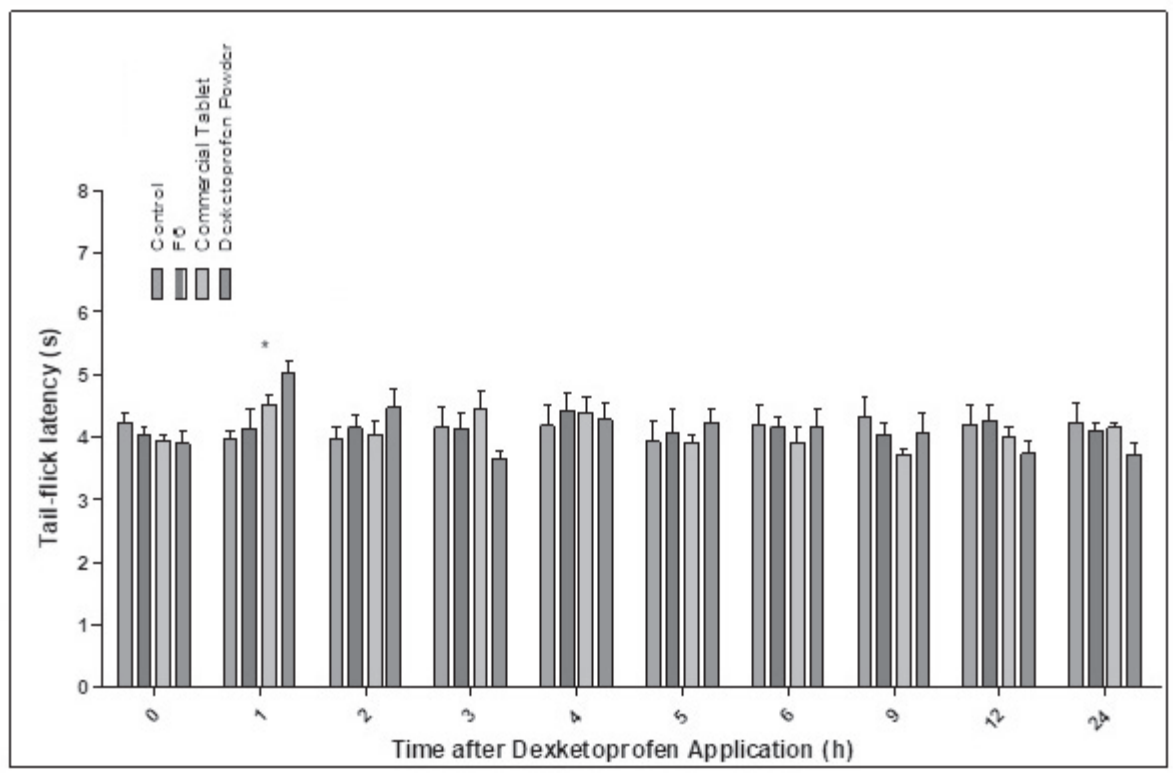

FIGURE 6 - The times between the applications of the thermal stimulus to the tail skin and the tail-flick responses after DT application. 


\section{DISCUSSION}

In the present study, HPMC (High or low viscosity), Eudragit and Carbopol were used as a polymer in the preparation of different types of matrix tablets in order to examine their effects on DT release. The amounts of DT in all formulations were the same, while polymer ratios were different to obtain different drug release rates. The tablets were prepared using wet granulations or direct compressions. The contents of the tablet formulations are given in Table I. The HPMC polymer has been for slow drug release or for sustained release preparations (Viriden, Wittgren, Larsson, 2009; Viriden et al., 2011; Espinoza, Hong, Villafuerte, 2000), and has also been used in controlled release tablets. The aim was to prepare tablets with bioadhesive properties to allow gastrointestinal retention for longer drug releases (Mehuys, Varvaet, Remon, 2004; Jaipal et al., 2015), and it is for this reason that HPMC was selected. HPMC exhibits bioadhesive properties and $\mathrm{pH}$ independent release, and the release of the active substance has not been reported to be significantly affected by the microenvironment (Ribeiro, Ferreira, Veiga, 2005; Streubel et al., 2000). HPMC therefore, was thus assessed to be the most appropriate polymer. Formulation F6 was less effected by $\mathrm{pH}$ in the release of the active substance. The pKa of DT, however, is 5.9 (Chandrasekharan, 2007), and so more DT was dissolved faster in an alkaline medium. A higher $\mathrm{pH}$ causes the formation of a porous structure in the tablet matrix, and so the release of DT increases with $\mathrm{pH}$. This was clearly observed in the present study in that when the $\mathrm{pH}$ of the medium was increased, the release of DT also increased. The polymer forms a gel and fills the porous matrix, and this event prevents drug release, which may be dominant especially in later time periods. Accordingly, shortly after the rise of $\mathrm{pH}$ of the dissolution medium, DT begins to dissolve rapidly, although HPMC prevents fast release, thus regulating the overall release (Figure 1). Although the weight variations were determined to be less than $2 \%$, and some formulations released more than $100 \%$ DT, no experimental results were excluded. It was possibly because of weight variations or DT contents. This was noted and pointed out; DT releases from formulations were checked further, and no stability problems or other negative effects were identified. The effect of $\mathrm{pH}$ was also aimed to be determined, and to this end, the Pharmacopoeia method USP 31, method A was used for the dissolution test of the prepared tablets.
Kinetic analyses indicated that the F6 formulation results fitted into the zero order release kinetic $(\mathrm{r} 2=0.938)$ and gave the closest dissolution to the theoretical target release. The release profiles of the other formulations were also examined, but none gave superior results.

The theoretical target line was also depicted in the dissolution profiles in figures, and the F6 formulation gave the closest release to the desired time period. This theoretical release line was calculated taking the pharmacokinetic parameters of DT into account, as mentioned in the method section. The target release should be terminated after 18.224 hours, and the best formulation was found to be F6, considering both the release rate and the time period.

The Pythia computer program was used to understand the effective formulation parameters and to estimate the release of DT\%. An ANN analysis program made use of the obtained results to investigate whether it was possible to predict the parameters or ingredient percentages of the desired product or formulation. The ANN model can be used for the estimation of the effects of many parameters, creating a mathematical modeling system (Degim et al., 2003; Degim, 2005). The materials used in the obtained formulation and experimental data (release \%) can be used for the successful prediction of drug release, and a very good relationship was identified between the experimental and predicted values (Figure 2). All 3D graphics and relations indicated that the relationship between the parameters and the experimental results was highly complex (all graphics in Figure 3). The results show that the Pythia program can be used and successfully applied to experimental results, without needing to resolve these complex relations.

The carrageenan-induced paw oedema model for the determination of anti-inflammatory effects has been used for the testing of formulations in literature (Dogrul et al., 2007), and so the same model was used in the present study on rats, with oedema volume measurements made at $0,1,2,3,4,5,6,9,12$ and 24 hours. A commercial formulation was designed to release drug immediately to obtain a rapid effect, and the effects of the commercial product and F6 in our in vivo experiments were determined to be the same, but statistically different from the control group $(p<0.01)$. Similarly, it was found that the marketed and F6 formulation significantly decreased the volume of paw oedema. The analgesic effect can be determined from tail-flick latencies (Rahman et al., 2002; Delporte 
et al., 2007). Our results show that (Figure 5 and 6) the selected formulation was effective, as were the commercially available formulations. All results were given as mean \pm standard errors. The data was analyzed with a two-way analysis of variance and a Bonferroni test, revealing the differences between the groups. The statistical analyses were thus found to be suitable and successful, and so no further analysis was made.

\section{CONCLUSION}

In conclusion, the test results of formulation F6 indicated that it is as effective as a commercial product. While the design of in vivo experiments may not facilitate the demonstration of any sustained effect, all of the experimental results presented here can be considered evidence of the effectiveness of the F6 formulation. None of the rats died after the administered doses, and it was concluded that the formulation presented no acute toxic effects. Furthermore, no animals were observed to suffer associated problems.

The prepared tablets (F6) were found to be as effective as the marketed painkillers, although the superiority of the prepared tablet was in its ability to sustain the effect for 24 hours. In addition, the prepared tablets exhibited their effect with lower doses, and so possible side effects may be minimized. The prepared tablets contain only the sustained dose, and if necessary two tablets can be taken together to enhance the effect. Accordingly, in some exceptional cases a rapid increase in blood concentration can be obtained with the administration of an initial conventional tablet, and the blood levels maintained with the developed controlled release tablets. In very extreme cases, if a much higher blood level is desired, it can be achieved with a greater initial dose.

Finally, it is possible that this tablet form can be used to achieve the targeted or desired blood levels, as described above, and this may be a suitable for different treatment alternatives or for individualized therapy. It can be concluded that the approach, techniques and results of the present study could lead to the development of new dosage forms for other similar drugs.

\section{REFERENCES}

Achanta AS, Kowalski JG, Rhodes CT. Artificial neural networks: implications for pharmaceutical sciences. Drug Dev Ind Pharm. 1995;21(1):119-155.
Barbonaj MJ, Antonijoan RM, Gich I. Clinical pharmacokinetics of dexketoprofen. Clin Pharmacokinet. 2001;40(4):245-262.

Beltran J, Martin-Mola E, Figueroa M, Granados J, Sanmarti R, Artigas R, Torres F, Forns M, Mauleon D. Comparison of dexketoprofen trometamol and ketoprofen in treatment of osteoartrits of the knee. J Clin Pharmacol. 1998;38(S1):74-80.

Benardos PG, Vosniakos GC. Optimizing feed forward artificial neural network architecture. Eng Applic Artificial Intelligence. 2007;20(3):365-382.

Bourne DWA. Pharmacokinetics. In: Banker GS, Rhodes CT. Modern Pharmaceutics. USA: Marcel Dekker; 2002, p.67-91.

Bourquin J, Schmidli H, Hoogevest $\mathrm{P}$, Leuenberger $\mathrm{H}$. Advantages of artificial neural networks (ANNs) as alternative modelling technique for data sets showing nonlinear relationships using data from a galenical study on a solid dosage form. Eur J Pharm Sci. 1998a;7(1):5-16.

Bourquin J, Schmidli H, Hoogevest $\mathrm{P}$, Leuenberger $\mathrm{H}$. Application of artificial neural networks (ANN) in the development of solid dosage forms. Pharm Dev Technol. 1997;2(2):111-121.

Bourquin J, Schmidli H, Hoogevest P, Leuenberger H. Pitfalls of artificial neural networks (ANN) modelling technique for data sets containing outlier measurements using a study on mixture properties of a direct compressed dosage form. Eur J Pharm Sci. 1998b;7(1):17-28.

Chandrasekharan NV. Dexketoprofen. Brigham Young University, USA: Elsevier; 2007, p.1-4.

Chansanroj K, Petrovic J, Ibric S, Betz G. Drug release control and system understanding of sucrose esters matrix tablets by artifical neural networks. Eur J Pharm Sci. 2011;44(3):321-331.

Chen Y, McCall TW, Baichwal AR, Meyer MC. The application of an artificial neural network and pharmacokinetic simulations in the design of controlled-release dosage forms. J Control Release. 1999;59(1):33-41.

D' Amour FE, Simit DL. A method for determining loss of pain sensation. J Pharmacol Exp Ther. 1941;72(1):74-79.

Degim IT. A review. Understanding skin penetration: computer aided modelling and data interpretation. Curr Comp-Aided Drug Design. 2005;1(1):11-19.

Degim T, Hadgraft J, Ilbasmis S, Ozkan Y. Prediction of skin penetration using artificial neural network (ANN) modelling. J Pharm Sci. 2003;92(3):656-664. 
Delporte C, Backhouse N, Inostroza V, Aguirre MC, Peredo N, Silva $X$, Negrete R, Miranda HF. Analgesic activity of Ugni molinae (murtilla) in mice models of acute pain. J Ethnopharmacol. 2007;112(1):162-165.

Dias FM, Antunes A, Mota AM. Artificial neural networks: a review of commercial hardware. Eng Applic Artificial Intelligence. 2004;17(8):945-952.

Dogrul A, Gülmez SE, Deveci MS, Gül H, Ossipov MH, Porreca F, Tulunay FC. The local antinociceptive actions of nonsteroidal anti inflammatory drugs in the mouse radiant heat tail-flick test. Anesth Analg. 2007;104(4):927-935.

Espinoza R, Hong E, Villafuerte L. Influence of admixed citric acid on the release profile of pelanserin hydrochloride from HPMC matrix tablets. Int J Pharm. 2000;201(2):165-173.

Iohom G,Walsh M, Higgins G, Shorten G. Effect of perioperative administration of dexketoprofen on opioid requirements and inflammatory response following elective hip arthroplasty. Br J Anaesth. 2004;88(4):520-526.

Jaipal A, Pandey MM, Charde SY, Raut PP, Prasanth KV, Prasad RG. Effect of HPMC and mannitol on drug release and bioadhesion behaviour of buccal discs of buspirone hydrochloride: In-vitro and in-vivo pharmacokinetic studies. Saudi Pharm J. 2015;23(3):315-326.

Jovanovic M, Jovicic G, Duric Z, Agbaba D, Karljikovic-Rajic K, Radovanovic J, Nikolic L. Effect of fillers and lubricants on acetylsalicylic acid release kinetics from Eudragit matrix tablets. Drug Dev Ind Pharm. 1997a;23(6):595-602.

Jovanovic M, Jovicic G, Duric Z, Agbaba D, KarljikovicRajic K, Nikolic L, Radovanovic J. The influence of Eudragit type on the dissolution rate of acetylsalicylic acid from matrix tablets. Acta Pharm Hung. 1997b;67(6):229-234.

Kesavan JG, Peck GE. Pharmaceutical granulation and tablet formulation using neural networks. Pharm Dev Technol. 1996;1(4):391-404.

Mabrouk MM, Hammad SF, Fatatry HM, El-Mala S. Spectroscopic methods for determination of dexketoprofen trometamol and tramadol $\mathrm{HCl}$. Inventi Impact Pharm Anal Quality Assurance. 2014;4:276-282.

Mehuys E, Varvaet C, Remon V. Hot-melt extruded ethylcellulose cylinders containing a HPMC-Gelucire core for sustained drug delivery. J Control Release. 2004;94(23):273-280.
Petrovic J, Ibric S, Bets G, Duric Z. Optimization of matrix tablets controlled drug release using elman dynamic neural networks and decision trees. Int J Pharm. 2012;428(1-2):57-67.

Rahman MT, Begum N, Alimuzzaman M, Khan MOF. Analgesic activity of Enhydra fluctuans. Fitoterapia. 2002;73(7-8):707-709.

Rekhi GS, Nellore RV, Hussain AS, Tillmean LG, Malinowski HJ, Ausburger LL. Identification of critical formulation and processing variables for metoprolol tartarate extended release tablets. J Control Release. 1999;59(3):327-342.

Ribeiro L, Ferreria DC, Veiga FJ. In vitro controlled release of vinpocetine- cyclodextrin - tartaric acid multicomponent complexes from HPMC swellable tablets. J Control Release. 2005;103(2):325-339.

Streubel A, Siepmann J, Dashevssky A, Bodmeier R. pH - independent release of a weakly basic drug from water - insoluble and soluble matrix tablets. J Control Release. 2000;67(1):101-110.

Takahara J, Takayama K, Nagai T. Multi-objective simultaneous optimization technique based on an artificial neural network in sustained release formulations. J Control Release. 1997;49(1):11-20.

Takayama K, Fujikawa M, Nagai T. Artificial neural networks as a novel method to optimize pharmaceutical formulations. Pharm Res. 1999;16(1):1-6.

Takka S, Rajbhandari S, Sakr A. Effect of anionic polymers on the release of propranolol hydrochloride from matrix tablets. Eur J Pharm Sci. 2001;52(1):75-82.

Viriden A, Alami SA, Wittgren B, Larsson A. Release of theophylline and carbamazepine from matrix tabletsconsequences of HPMC chemical heterogeneity. Eur J Pharm Biopharm. 2011;78(3):470-479.

Viriden A, Wittgren B, Larsson A. Investigation of critical polymer properties for polymer release and swelling of HPMC matrix tablets. Eur J Pharm Sci. 2009;36(2-3):297-309.

Wu T, Pan W, Chen J, Zhang R. Formulation optimization technique based on artificial neural network in salbutamol sulfate osmotic pump tablets. Drug Dev Ind Pharm. 2000;26(2):211-215.

Received for publication on $05^{\text {th }}$ July 2018 Accepted for publication on $13^{\text {th }}$ November 2018 